\title{
Vaginismo - Sugestão de processo terapêutico passo a passo
}

Jaqueline Brendler ${ }^{1}$

Zeila Bedin ${ }^{2}$

\section{RESUMO}

Como o objetivo de contribuir e encorajar os terapeutas que estão iniciando suas atividades na área de sexualidade humana, descreve-se passo a passo as técnicas da terapia sexual utilizadas na resolução de um caso de Vaginismo de longa duração. O casal participou de duas sessões terapêuticas por semana, uma com a terapêuta sexual a outra com a psicóloga clínica. Após a sexta semana de sessões terapêuticas ocorreu a resolução do Vaginismo.

\section{INTRODUÇÃO}

O Vaginismo é uma Síndrome Psicossomática $(1,4,8,10)$ que se não tratado pode privar o casal do Relacionamento Sexual e de ter filhos (1 ,4). É causa comum de Casamento não Consumado $(4,8)$.

1. Ginecologista e obstetra.

2. Psicóloga Clínica. 
A maioria dos terapeutas do sexo têm índices de 100 por cento de cura quando a paciente completa o período de tratamento $(1,4)$.

\section{$1^{\mathrm{a}}$ e $2^{\mathrm{a}}$ Sessões}

L. H. A, vem ao consultório encaminhada por um ginecologista. Sexo feminino, mulata, 31 anos, casada. É bancaria, natural e residente de Porto Alegre. Católica não praticante. Formada em Ciências Contábeis. Vem acompanhada do marido J. A., 34 anos, taxista, natural e procedente de Porto Alegre. Católico não praticante, tem $2^{\circ}$ grau completo. Pertence a direção de uma Escola de Samba.

L. H. A. diz ter vindo consultar porque quer engravidar. Há seis anos está casada e não teve relação sexual com penetração. Não consegue fazer exame ginecológico. $\mathrm{O}$ ginecologista diz que tem vaginismo.

A paciente informa em sua consulta individual que é filha do meio. Tem dois irmãos mais velhos. A mãe não falava sobre sexo em casa. Aprendeu o que sabe sobre sexo no colégio e com as amigas. Lembra que quando era solteira uma amiga que casou virgem disse que sexo "doía". O pai, durante o namoro com J. A., somente lhe perguntou se tomava pílula, ao que ela respondeu que sim.

Namoraram sete anos. Após o primeiro ano de namoro iniciaram as tentativas de relação sexual, quando tinha 20 anos. Ela foi a segunda namorada de J. A. e ele o seu primeiro namorado.

Casou com 25 anos, antes de terminar a Faculdade. Diz que naquela época ficavam menos tempo juntos, pois trabalhava e estudava. Procurou vários médicos para tentar resolver o problema e eles disseram para "ir tentando. A família do casal não sabe da dificuldade sexual.

Diz que tem vontade de ter relações sexuais. Sempre, desde o início do namoro, quando estão juntos, há troca de carinho. Diz que fica molhada e que tem orgasmo. Diz que J. A. tem ereção boa. Diz que pensa durante o dia que vai conseguir ter relação sexual e na hora desiste porque "tem medo da dor".

Diz que J. A. nunca foi de manifestar muito o que sente, mas no tempo de namoro ele escrevia bilhetes e cartões. Era mais "ligado em mim". "Amo o J. A.". Sente falta dele. Ele não fala espontaneamente que a ama. Só fala se ela perguntar.

Há dois anos atrás ficou sabendo de uma relação extra-conjugal de J. A. Era uma mulher da Escola de Samba. J. A. falou que o caso durou um ano e que resolveu contar porque a amante estava fazendo chantagem. A amante de J. A. foi à sua casa. Ela disse que era virgem e ficou imprestá- 
vel, pois havia engravidado e feito aborto. Recebeu a amante do marido após chamar seu pai, que junto ouviu a história. J. A. negou o aborto. Nunca saiu de casa. L. H. A. imaginava que ele ia embora. Diz que jamais teria um caso. "Eu primeiro terminaria com J. A.; não trairia". Diz que chorou naquela ocasião.

L. H. A. tem medo da Penetração doer. Diz que acha o pinto grande demais para entrar sem machucar. L. H. A. nega tentativa de relação sob coersão. Nega ter visto ou ouvido cena sexual violenta, ou outras agressões sexuais.

Quanto à J. A., ele diz que é o terceiro filho de uma família de oito irmãos, iniciou sua vida sexual com uma conhecida na época do quartel. O relacionamento foi bom. O que sabe sobre relação sexual aprendeu no colégio Mesquita. Conta que nas primeiras relações sexuais a sua preocupação era com o desempenho.

Teve uma namorada antes de L. H. A.. Ela era virgem. Tiveram relação sexual completa e "normal". Diz que relação sexual "normal" é quando existe penetração e os dois gozam.

No primeiro ano de namoro com L. H. A, tentaram relação sexual no motel e em vários lugares. Ambos tinham prazer. L. H. A. tomava pílula porque não queriam filhos antes do casamento. Considera que a relação sexual era boa porque "gosto dela, é uma boa pessoa". L. H. A. tinha curiosidade sobre o relacionamento sexual com sua primeira namorada. Colocou L. H. A. na parede. Ou casa comigo ou volto para a minha primeira namorada”. L. H. A. aceitou casar.

No início do casamento acha que tinham uma "barreira" porque, durante o sexo, pensava na primeira namorada diz que evitava relação sexual e ejaculava rápido.

Sobre o caso mencionado pela mulher, diz que a amante era uma chantagista, queria dinheiro. Nunca havia engravidado. Teve outro caso: com uma amiga deles. A L. H. A. nunca soube. Essa sim engravidou. Foi com ela fazer o aborto. O relacionamento esfriou após o aborto. um aborto.

Hoje pensa que a situação atual seja "castigo de Deus", porque fez

\section{CONDUTA}

1. A entrevista inicial foi realizada primeiro com o casal e após com cada um isoladamente. Teve a duração de duas sessões por semana. Definiu-se que deveriam ter um acompanhamento Psicológico com uma sessão por semana, o marido faria uma consulta com o Urologista. 
2- Foi esclarecido que o resultado do tratamento dependeria muito do esforço do casal, no sentido de realizar as tarefas propostas.

3- Foi explicado conceito de Vaginismo. Orientado quanto a anormalidade do casal quanto as fases da resposta sexual.

4- Incentivo ao namoro, às demostrações de afeto e introduzido um conceito amplo de sexualidade.

5- Sugerido e exposto Foco Sensório 1.

6- Proibido tentativa de relação sexual.

7- Sugerido e ensinado Exercícios de Kegel.

\section{Avaliação Psicológica Inicial} tologia.

A paciente casada com J. A., não apresentava quadro de psicopa-

Casal apresentava bom relacionamento afetivo, e desenvolviam jogos sexuais a amorosos prazeirosos. Entretanto, não obtiveram um relacionamento sexual com penetração.

Não houvesse a intenção de engravidar, talvez a situação fosse mantida por mais tempo.

$\mathrm{Na}$ consulta psicológica a paciente revelou forte dependência da aprovação familiar, principalmente do pai, que ela considerava superior (apesar de ser de "cor", tinha se formado e exercia advocacia).

Até o presente momento a família não tinha conhecido, a Situação do casal. A cobrança aparecia, quando questionados sobre filhos'.

Teve uma educação pseudo-liberal.

De religião católica, moral rígida no sentido de valorizar "virgindade", "casar certinho", "não engravidar".

Quando noiva, o pai apenas sugeriu que tomasse "pílula" para não engravidar. Em sua casa não se falava sobre sexo. Quando era comentado, era para citar algum caso de gravidez fora do casamento, moças liberais e outros.

Antes do casamento, teve várias tentativas de relacionamento, man sempre "preocupada" em manter a virgindade ("Não queria desagradar o pai" - Imaginava se engravidasse!).

O marido era passivo. Concordava muito com a mulher e não queria magoá-la. Como não obtivesse com ela uma resolução plena, optou por um relacionamento extra-conjugal, onde ficou claro que ele não tinha problemas.

Tal relacionamento foi esclarecido na presença do pai da paciente.

Depois desse episódio, decidiram pela Terapia Sexual, com Psicoterapia Conjugal breve Associada. 


\section{$3^{\text {a }}$ Sessão}

- Trabalho resistência ao Foco Sensório I.

- Feito exame Ginecológico. Declarada normalidade da genitália para a paciente.

- Visualização da genitália pela paciente com o auxílio de um espelho. A paciente estava em posição ginecológica. Feito esclarecimento de dúvidas sobre órgãos sexuais. Feito exercícios de Kegel em posição ginecológica em frente ao espelho. A paciente observa o espasmo vaginal provocado pelo Vaginismo.

- Após a pesquisa de cenas ansiogênicas foi iniciado Dessensibilização Sistemática Progressiva.

- Novos esclarecimentos sobre genitais masculinos e Fases da Resposta Sexual.

\section{CONDUTA}

1- Incentivo à imaginação no Foco Sensório I.

2- Exercício de Kege.

3- Proibição Relação Sexual.

4- Sugiro Descarga Ejaculatória.

5- Sugiro dilatação vaginal pela paciente usando primeiro o $5^{\circ}$ dedo da mão e posteriormente usando dois dedos para essa tarefa sugiro lugar tranqüilo. Após o relaxamento muscular "Dessesibilização".

\section{$4^{\mathrm{a}}$ Sessão}

O casal está mais confiante. Realizaram as tarefas propostas. L. H. A. realizou com facilidade dilatação unidigital. Refere que com a dilatação bidigital teve um pouco de dificuldade e desconforto.

- Converso com o casal sobre namorar e a demostração de afeto.

- Recebo avaliação urológica feita por J. A. onde não foi constatado problema físico.

- Feita Dessensibilização de Kegel na frente do espelho em posição ginecológica.

- Na presença do marido, estando a paciente ainda em posição ginecológica, oriento sobre a normalidade do exame físico da paciente. 
Nas três tarefas seguintes a paciente permaneceu em posição ginecológica na presença do marido:

- Com a luva ginecológica a paciente faz dilatação vaginal com um e posteriormente com dois dedos, sem dificuldades.

- Sob orientação, a paciente faz exercícios de Kegel simultâneos à dilatação vaginal. Saliento que ela pode sentir que exerce um certo controle voluntário sobre a entrada da vagina.

- Sugiro que o marido tente fazer dilatação vaginal digital com luva ginecológica. A paciente permite. A essa dilatação foi associada, posteriormente, Exercício de Kegel.

\section{CONDUTA}

1- Todas as cinco tarefas da $3^{\mathrm{a}}$ consulta.

2- Sugiro que o marido participe da dilatação vaginal.

3- Sugiro que a dilatação vaginal seja feita concomitante aos Exercícios de Kegel.

4- Sugiro que a paciente após o relaxamento muscular fantasie uma Relação Sexual em que o marido está deitado e ela, após segurar o pênis ereto, o introduz na vagina. Mostro ao casal desenhos da posição sugerida. (Manual Ilustrado de Terapia Sexual - KAPLAN)

\section{$5^{\mathrm{a}}$ Sessão}

L. H. A. vem à consulta sozinha. Informa que o marido está mais espontâneo na demostração afetiva. Diz que está com dificuldades para imaginar-se sendo penetrada. Fizeram todas as tarefas propostas na consulta anterior.

A paciente refere ter colocado, espontaneamente, um absorvente interno e o deixado por 12 horas sem desconforto.

A consulta segue modelo da consuta anterior. Após a paciente insistir que o pênis do marido é muito maior que os dois dedos que introduz na vagina. Introduzo um Amnioscópico lubrificado. A paciente encontra-se em posição ginecológica e o Amnioscópico não foi mostrado a paciente antes da introdução. A paciente ficou surpresa ao ver o Amnioscópico sendo retirado de sua vagina, pelo seu tamanho e encorajada pois ele "É maior que o pinto duro". 


\section{CONDUTA}

1- Acrecento às tarefas até aqui sugeridos detalhes como a movimentação anterior, posterior e lateral dos dedos na dilatação vaginal.

2- A pedido da paciente empresto o Amnioscópico para ela realizar dilatação vaginal. Sugiro que ela olhe a introdução.

3- Oriento e incentivo Foco Sensório 11.

\section{6 $^{\text {a Sessão }}$}

Não compareceram em duas sessões terapêuticas consecutivas por causa das festas de final de ano. Trabalho resistência do casal ao avanço da terapia.

Nesse tempo o casal realizou as tarefas sugeridas embora com menor frequiência do que nas outras vezes. L. H. A. diz que está com mais facilidade para imaginar-se sendo penetrada. Não sentiu desconforto à introdução do Amnioscópico.

Durante a consulta, após Dessensibilização Sensório Progressiva e dilatação vaginal digital, na presença do marido, a paciente foi encorajada a introduzir o Amnioscópico deitada, sentada e acocorada na cama ginecológica. As tarefas foram realizadas sem dificuldades. Ainda o Amnioscópico foi rodado dentro da vagina pela paciente.

A paciente diz sentir-se segura para tentar relação sexual com penetração.

\section{CONDUTA}

1- Estímulo e continuação da troca de carinho.

2- Libero Posição Coital com a paciente em posição superior comandado com a mão à introdução peniana. Sugiro que o pênis permaneça sem movimento.

\section{$7^{\mathrm{a}}$ Sessão}

O casal conseguiu penetração com a posição sugerida. A paciente relata que movimentou o pênis dentro da vagina. A paciente achou muito prazerosa a relação. Diz que está "curada". Dado apoio e encorajamento ao casal. Alta da Terapia Sexual. 


\section{Resumo da Avaliação Psicológica}

A Terapeuta Sexual desenvolveu o trabalho de Dessensibilização a Foco Sensório, concomitantemente, desenvolvemos um trabalho de conscientização de sua resistência e de seus conflitos. Seu padrão de comportamento era evitar a penetração (com medo da dor). Foi desenvolvido um trabalho de esclarecimento sobre sexualidade, sobre desenvolvimento sexual, de forma compreensiva e educativa. Foi esclarecido junto a paciente e ao casal, as etapas da evolução sexual, elaborando alguns preconceitos e tabus. Tudo foi discutido até que o casal se sentisse seguro e conhecedor do processo terapéutico, e da evolução do tratamento.

A paciente pode entender sua reação e seus sentimentos que despertavam nela a relação sexual. Entendeu seu relacionamento familiar a sua dependência da aprovação paterna. Sentiu que precisava "crescer" e se assumir como "mulher". Tinha que deixar de ser a "filhinha protegida pelo pai", de ter medo de desagradá-lo.

Paralelo a isso, a terapia sexual evoluía. A colaboração da paciente também.

A paciente foi sendo preparada gradativamente, para aceitar a penetração como um fato "um pouco desagradável, talvez doloroso", mas necessário para uma resolução sexual plena, principalmente, para uma resolução comp pessoa,

Após seis sessões, o canal teve a primeira relação com penetração.

A terapia combinada, Terapia Sexual mais Terapia Breve, foi o tratamento escolhido neste caso. O resultado foi positivo e o canal se beneficiou no sentido de que, além da resolução de sua difunção sexual, desenvolveu um melhor conhecimento de seu relacionamento inter-pessoal e de suas possibilidades como casal.

$\mathrm{Na} 8^{\mathrm{a}}$ sessão o casal teve alta.

\section{DISCUSSÃO}

O Vaginismo é uma Síndrome Psicofisiológica caracterizada por espasmo involuntário dos músculos que circundam a entrada da vagina e o músculo elevador do ânus. Ocorre sempre que é feita uma tentativa para se introduzir um objeto no orifício vaginal ( I , 4, 6, 8, 10).

Mútiplos fatores Psicossocioculturais $(5,10)$ estão li1gados à gênese do vaginismo e seu reflexo condicionado resulta da associação de dor e medo das tentativas reais ou fantasiadas de penetração vaginal (5). 
Como recomendado por Masters e Johnson, o casal iniciou o aspecto experimental do tratamento com exercícios de Foco Sensório I e posteriormente foi empregado Foco Sensório II com o intuito de dissipar a ansiedade relacionada à performance sexual $(1,2,3,8,9)$.

Os exercícios de Kegel foram prescritos à fim de aumentar a percepção sensorial da vagina $(4,7)$ e ensinar a paciente a contrair e relaxar voluntamente os músculos em torno da vagina $(3,48)$. â

A proibição do coito diminui a fobia e a ansiedade em relação à penetração vaginal (8). Foi prescrita após a entrevista inicial.

$\mathrm{O}$ exame ginecológico realizado foi o primeiro passo da "Dessensibilidade Sistemática In Vivo- (8) e a visualização através do espelho do espasmo condicionado pelo vaginismo também é passo importante no início da terapia (1), Foi efetuado na $3^{\mathrm{a}}$ sessão terapêutica.

A paciente apresentou forte elemento fóbico associado: 1 . Medo da penetração causa dor; 2 . Medo e antecipação de dano físico provocado pela penetração. Para afastar a fobia foi iniciado "Dessensibilização Sistemática Progressiva" após pesquisas de cenas ansiogênicas $(4,8)$.

Para a maioria dos autores há um consenso sobre a necessidade da "Dessensibilização Sistemática In Vivo- para a extinção da resposta vaginal condicionada no tratamento do vaginismo $(3,4,5,6,8)$ que foi empregada no caso descrito a partir da $3^{a}$ consulta. Para prover o descondicionamento pode-se usar sondas, cateteres, tampão $(4,5)$, dilatadores de plástico (3) e os dedos da paciente e posteriormente os do marido $(4,5,6,8) . \mathrm{Na}$ maior parte do tratamento foram empregados os dedos por ser emocionalmente mais aceitável para a paciente e portanto ter menos probabilidade de mobilizar as resistências à terapia (6).

O marido participou do segundo exame ginecológico e das sessões de Dessensibilização In Vivo a partir da $2^{\mathrm{a}}$ sessão, com o objetivo de extinguir a mística em torno do vaginismo e promover o descondicionamento completo da -unidade conjugal" $(3,8)$. Outro fato importante é que o marido presencia os avanços da terapia sexual.

Com o Progresso da terapia e a fim de preparar a paciente para a liberação coital com ela comandando a introdução peniana em posição superior $(3,4,5)$ foi sugerido à paciente fantasias sob relaxamento com a posição descrita.

A movimentação dos dedos na vagina $(4,5,6,8)$ foi efetuada primeiro pole paciente e posteriormente pelo marido.

Masters e Johnson no passo que antecede a liberação coital uso um dilatador de plástico que com a mesma espessura do pênis ereto $(1,3)$. No caso citado, foi empregado o Amnioscópico de acrílico como último passo da Dessensibilização In Vivo, por ser o objeto disponível que mais se assemelha à espessura e o tamanho do pênis ereto. Esse fato foi decisivo no Descondicionamento In Vivo. 
Após a $6^{\mathrm{a}}$ sessão terapêutica a paciente relata sentir-se segura para ter Relação Sexual com penetração. O casal é liberado para o coito com a paciente em posição superior comandado com a ajuda da mão a introdução peniana. Foi sugerido apenas a introdução do pênis sem a sua movimentação $(3,4,5,8)$.

\section{REFERÊNCIAS BIBLIOGRÁFICAS}

1. MASTERS, W. H., JOHNSON, V. E.: Human sexual inadequacy. Boston, Little, Brow 7 Co, 1970.

2. MASTERS. W. H., JOHNSON, V. E.: Principles os the new sex therapy. Am. J. Paychiatry 133: 5, May, 1976.

3. MASTERS \& JOHNSON: O relacionamento amoroso. Segredos do amor e da intimidade sexual. Rio do Janeiro. Editora Nova Fronteira. 1974.

4. KAPLAN, H. S.: A nova terapia do sexo. Rio de Janeiro, Editora Nova Fronteira, 1974.

5. KARPLAN. H. S.: A nova terapia do sexo. Vol. 2. O desejo sexual e novos conceitos e técnicas da terapia do sexo. Rio de Janeiro. Editora Nova Fronteira, 1979.

6. KAPLAN, I. I. S.: Manual ilustrado de terapia sexual. São Paulo, Editora Manole, 1975.

7. KEGEL, Arnold H.: Sexual functions of the pubococcygeus muscle. Read before the eighty-firt annual-sesseion of California Medical Association, section en obstetrics and gynecology. Los Angeles, april 30, 1952.

8. REAMY, Kenneth: The treatment of 'Vaginismus by the Gynecologist: an ecletic aproach. Obstetrics \& Gynecology, vol. 59, n 1, january, 1982.

9. SILVA,A.C.:Terapia do sexo e dinâmica do casal. Rio de Janeiro, Editora Espaço e Tempo Ltda., 1989.

10. SOARES, L. G. L. e LOPES, G. P.: Vaginismo - Fatores psicossocioculturais. Revisal Brasileira de Sexualidade Humana. vol. II, n 2, pág. 127-130, 1991. 